\title{
Article \\ Quantitative Proteomic Profiling of Fungal Growth, Development, and Ochratoxin A Production in Aspergillus ochraceus on High- and Low-NaCl Cultures
}

\author{
Yan Wang ${ }^{1,2}\left(\mathbb{D}\right.$, Yue Guan ${ }^{1}$, Wei Lin ${ }^{1}$, Hao Yan ${ }^{3, *}$, Jing Neng ${ }^{1,2}$ and Peilong Sun ${ }^{1,2, *}$ \\ 1 College of Food Science and Technology, Zhejiang University of Technology, Hangzhou 310014, China; \\ wangyan062006@zjut.edu.cn (Y.W.); zjutgy2020@163.com (Y.G.); linwei5913@163.com (W.L.); \\ nengjing@zjut.edu.cn (J.N.) \\ 2 Key Laboratory of Food Macromolecular Resources Processing Technology Research (Zhejiang University of \\ Technology), China National Light Industry, Hangzhou 310014, China \\ 3 Zhejiang Provincial Center for Disease Control and Prevention, Hangzhou 310051, China \\ * Correspondence: hyan@cdc.zj.cn (H.Y.); sun_pl@zjut.edu.cn (P.S.)
}

check for updates

Citation: Wang, Y.; Guan, Y.; Lin, W.; Yan, H.; Neng, J.; Sun, P. Quantitative Proteomic Profiling of Fungal Growth, Development, and Ochratoxin A Production in Aspergillus ochraceus on High- and Low-NaCl Cultures. Toxins 2021, 13, 51. https://doi.org/10.3390/ toxins13010051

Received: 16 December 2020 Accepted: 30 December 2020 Published: 13 January 2021

Publisher's Note: MDPI stays neutral with regard to jurisdictional clai$\mathrm{ms}$ in published maps and institutional affiliations.

Copyright: (C) 2021 by the authors. Licensee MDPI, Basel, Switzerland. This article is an open access article distributed under the terms and conditions of the Creative Commons Attribution (CC BY) license (https:// creativecommons.org/licenses/by/ $4.0 /)$.

\begin{abstract}
Dry-cured meat products are worldwide food with high-salt content, and filamentous fungi are beneficial to the maturation process. However, some salt-tolerant strains of Aspergillus and Penicillium produce ochratoxin A (OTA) on these products and thus threaten food safety. In our study, proteomic analysis was performed to reveal the mechanism of adaptability to highsalt environment by Aspergillus ochraceus. Twenty g/L and $70 \mathrm{~g} / \mathrm{L} \mathrm{NaCl}$ substrates were used to provide medium- and high- $\mathrm{NaCl}$ content environments, respectively. The $\mathrm{NaCl}$ addition could induce fungal growth, but only $20 \mathrm{~g} / \mathrm{L} \mathrm{NaCl}$ addition could induce spore production while $70 \mathrm{~g} / \mathrm{L}$ repressed it. Proteomics analysis identified 2646 proteins in A. ochraceus fc-1, of which 237 and 251 were differentially expressed with $20 \mathrm{~g} / \mathrm{L}$ and $70 \mathrm{~g} / \mathrm{L} \mathrm{NaCl}$ addition, respectively. Potential factors affecting fungal growth and development were identified by GO and KEGG analyses of biological process, cellular component, and molecular function terms. The results revealed that ergosterol synthesis pathway was significantly upregulated with $20 \mathrm{~g} / \mathrm{L}$ and $70 \mathrm{~g} / \mathrm{L} \mathrm{NaCl}$ addition. However, fungal growth and development including OTA production were complex processes associated with many factors including nutrient uptake, cell membrane integrity, cell cycle, energy metabolism, intracellular redox homeostasis, protein synthesis and processing, autophagy, and secondary metabolism. Reactive oxygen species may be an important window to understand the mechanism that medium-salt content was conducive to intracellular signal transduction while highsalt content caused oxidative stress. The findings would help to improve the processes and storage conditions of dry-cured meat products.
\end{abstract}

Keywords: proteomics; ochratoxin A; Aspergillus ochraceus; salt; food safety

Key Contribution: The mechanism of adaptability to high-salt environment by Aspergillus ochraceus was studied. The ergosterol synthesis pathway was significantly upregulated with $\mathrm{NaCl}$ addition. $\mathrm{NaCl}$ addition concentrations can influence nutrient assimilation, energy metabolism, cell membrane integrity, response to oxidative stress, protein synthesis and processing, and secondary metabolism. The knowledge of the mechanism about adaption to high- $\mathrm{NaCl}$ environments by Aspergillus would help for OTA control in dry-cured products.

\section{Introduction}

In many food-processing processes, especially in the processing of meat products, the addition of table salt is necessary, which can improve the flavor and texture and can reduce water activity and inhibit the growth of microorganisms. Dry-cured meat products are worldwide high-salt-content food, and molds contribute to the development of the sensory 
qualities. However, some filamentous fungi of Aspergillus and Penicillium are able to grow on these $\mathrm{NaCl}$-rich substrates and produce Ochratoxin A (OTA) [1].

OTA is a potent nephrotoxic mycotoxin [2,3] and is classified as a Group 2B compound (a possible human carcinogen) by the International Agency for Research on Cancer. OTA, which was produced by P. verrucosum, P. nordicum, A. westerdijkiae, and A. ochraceus, was detected in dry-cured meat products including dry-cured sausages and hams $[4,5]$. However, the contamination of OTA in these food commodities received less attention and few countries and organizations established a maximum permissible level of OTA content. One $\mu \mathrm{g} / \mathrm{kg}$ of OTA was limited in fresh pork and derived meat products in Italy [1].

Medium- or high-salt concentration often accelerates the mycelial growth of $P$. verrucosum and $P$. nordicum, but the influence of salt on the OTA production remains, many argue, depending on the different types of strains. $\mathrm{NaCl}$ addition is usually in favor of OTA production [6]. In addition, OTA production may be beneficial for Penicillium's adaption to $\mathrm{NaCl}$-rich substrates [7]. In recent studies, natural preservatives (spices) and biocontrol (Debaryomyces hansenii) have shown potential of controlling OTA production by Penicillium in high-NaCl-content meat model $[8,9]$.

However, similar studies about Aspergillus remain limited. A. ochraceus could grow at low water activities and some strains even grow strongly at $37^{\circ} \mathrm{C}$, while its closely related species, $A$. westerdijkiae, would not grow at this temperature [10,11]. With increasing global warming, threat from A. ochraceus would become more considerable. A. ochraceus was likely to have greater growth rates in a medium supplied with certain concentrations of $\mathrm{NaCl}$ $(0-80 \mathrm{~g} / \mathrm{L})$, and the colony diameter was the largest at the salt content of $40 \mathrm{~g} / \mathrm{L}$. The capability of OTA production was inhibited when salt content was $40 \mathrm{~g} / \mathrm{L}$ in A. ochraceus [12]. The knowledge of the mechanism about adaption to high- $\mathrm{NaCl}$ environments by Aspergillus would help for OTA control in dry-cured products.

Proteomics is a powerful tool for determining the mechanisms of biochemistry for how A. ochraceus conform in NaCl-rich environments [13]. In this study, isobaric tags for relative and absolute quantification (iTRAQ)-based quantitative proteomic analysis were performed to research proteome changes in high- and low- $\mathrm{NaCl}$ conditions. The potential factors affecting fungal growth and development were identified based on GO (Gene Ontology) and KEGG (Kyoto Encyclopedia of Genes and Genomes) analyses of biological process, cellular component, and molecular function terms.

\section{Results}

\subsection{Influence of $\mathrm{NaCl}$ Addition on Mycelial Growth and Sporulation Ability of A. ochraceus}

With the addition of $\mathrm{NaCl}$, the mycelial growth and the sporulation ability of $A$. ochraceus were significantly changed. The influence of $\mathrm{NaCl}$ addition on the fungal mycelial growth is shown in Figure 1A. The mycelial diameter was $20.1 \%$ and $18.6 \%$ increased when 20 and $70 \mathrm{~g} / \mathrm{L} \mathrm{NaCl}$ were added compared to control, respectively. As shown in Figure 1B, the growth rates at 36, 72, and $84 \mathrm{~h}$ were lower than control samples when $70 \mathrm{~g} / \mathrm{L} \mathrm{NaCl}$ was added, while the growth rates were much higher at $48 \mathrm{~h}$ and $60 \mathrm{~h}$. The mycelial growth was significantly accelerated in culture times of $36-60 \mathrm{~h}$ and it resulted in the final length of the mycelial being larger than the control group when $70 \mathrm{~g} / \mathrm{L} \mathrm{NaCl}$ was added. The growth rate was higher than $20 \%$ except the value at $60 \mathrm{~h}$ when $20 \mathrm{~g} / \mathrm{L} \mathrm{NaCl}$ was added. However, the mean growth rate of control samples was $18.1 \%$, and it indicated that $20 \mathrm{~g} / \mathrm{L}$ $\mathrm{NaCl}$ addition could stably promote fungal growth. 

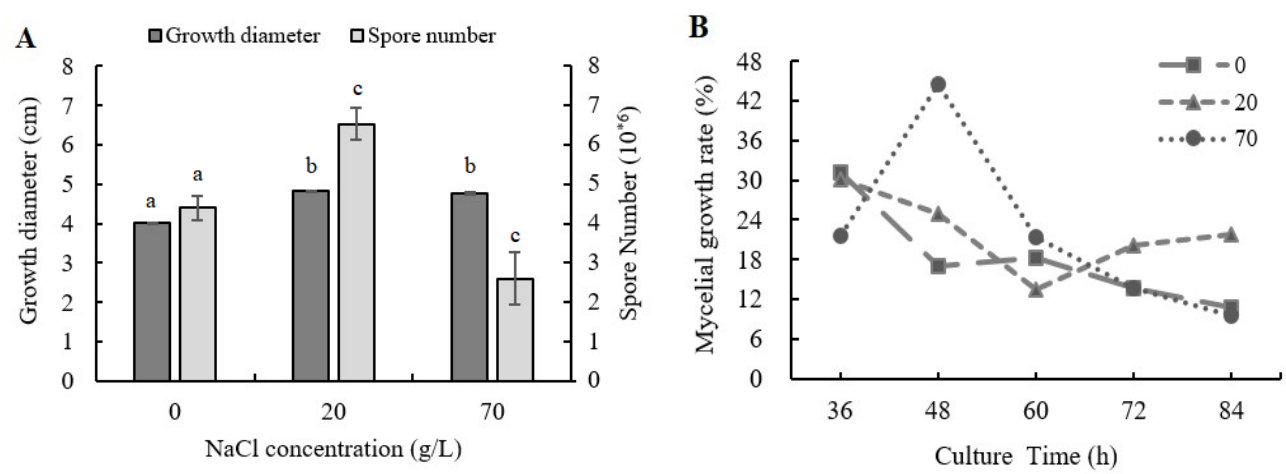

Figure 1. The mycelial diameter and spore production amounts after four days of culture with $\mathrm{NaCl}$ addition. (A) Mycelial diameter and spore number were measured after four days of culture in PDA medium with $\mathrm{NaCl}$ addition. (B) Growth rates were measured in four days of culture in PDA medium with $\mathrm{NaCl}$ addition. Results are presented as the mean of three repetitions. Different letters indicate a significant difference between the corresponding values $(p<0.05)$.

The influence of $\mathrm{NaCl}$ addition on the fungal sporulation ability is shown in Figure 1A. The capacities of spore producing were $48.4 \%$ increased with $20 \mathrm{~g} / \mathrm{L} \mathrm{NaCl}$ addition and were $41.0 \%$ decreased with $70 \mathrm{~g} / \mathrm{L} \mathrm{NaCl}$ addition, respectively.

\subsection{Influence of $\mathrm{NaCl}$ Addition on OTA Production of A. ochraceus}

The influence of $\mathrm{NaCl}$ addition on OTA production of $A$. ochraceus is shown in Figure 2. Low concentration of $\mathrm{NaCl}$ could promote OTA production, while higher concentration inhibits it; $1.827 \mathrm{ppm}$ OTA was detected with $20 \mathrm{~g} / \mathrm{L} \mathrm{NaCl}$ addition $(72.7 \%$ higher than control samples) and only $0.033 \mathrm{ppm}$ OTA was detected in the samples with $70 \mathrm{~g} / \mathrm{L}$ $\mathrm{NaCl}$ addition.

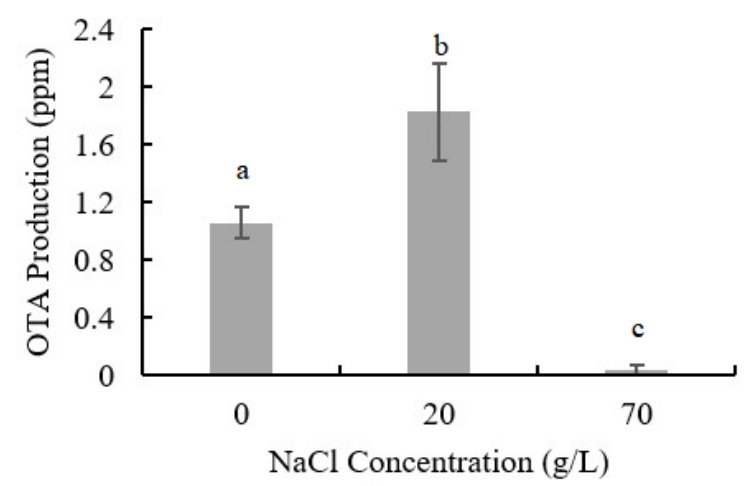

Figure 2. OTA production in seven days of culture in PDA medium with $\mathrm{NaCl}$ addition. Results are presented as the mean of three repetitions. Different letters indicate a significant difference between the corresponding values $(p<0.05)$.

OTA content is an important indicator to measure the safety of foods such as cereals and dry-cured meat products, and our results indicated that low concentration of $\mathrm{NaCl}$ may increase the risk of OTA accumulation. Proteomics analysis was further performed to reveal the mechanism of fungal growth, development, and OTA production in environments of low- or high- $\mathrm{NaCl}$ concentrations.

\subsection{Alteration of Proteins with or without $\mathrm{NaCl}$ Addition}

The comparison between the samples with $20 \mathrm{~g} / \mathrm{L} \mathrm{NaCl}$ added or without was named group A, while that with $70 \mathrm{~g} / \mathrm{L} \mathrm{NaCl}$ added or without was named group $\mathrm{B}$. A total of 2646 proteins were identified. There were 237 differentially expressed proteins (DEPs) identified $\left(\mid \log _{2}\right.$ ratio $\left.\mid>1.5, p<0.05\right)$, of which 131 were upregulated and 106 were 
downregulated in group A; 251 DEPs were identified ( $\mid \log _{2}$ ratio $\mid>1.5, p<0.05$ ), of which 126 were upregulated and 125 were downregulated in group B. As shown in Figure 3, 126 proteins were found both regulated in two groups, of which 66 proteins were upregulated and 60 proteins were downregulated. The alternation number of proteins in group $B$ was larger than group $\mathrm{A}$, indicating that $70 \mathrm{~g} / \mathrm{L} \mathrm{NaCl}$ addition may cause more influence on the growth and development of $A$. ochraceus than does $20 \mathrm{~g} / \mathrm{L} \mathrm{NaCl}$ addition.

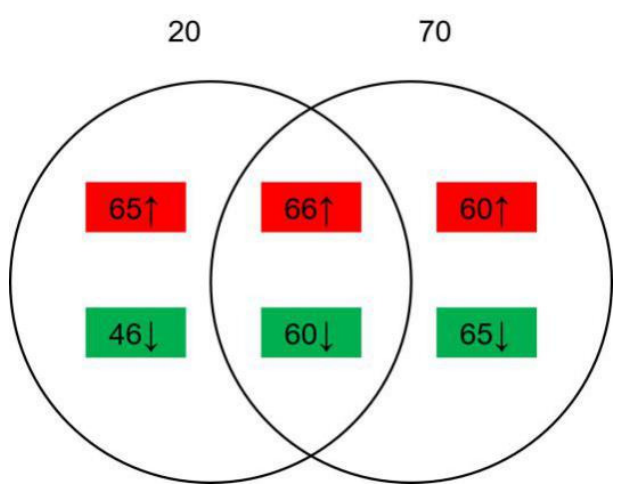

Figure 3. Identified differentially expressed proteins (DEPs). Red or $\uparrow$ represents significantly upregulated proteins and green or $\downarrow$ represents significantly downregulated proteins. Group A, $20 \mathrm{~g} / \mathrm{L} \mathrm{NaCl}$ addition vs. control; Group B, $70 \mathrm{~g} / \mathrm{L} \mathrm{NaCl}$ addition vs. control.

\subsection{Hierarchical Clustering, Functional Classification, and Enrichment Analysis of DEPs}

Hierarchical cluster analysis was performed on DEPs, and the results are shown in Supplementary Figure S1. The clustering results of target proteins can help us distinguish protein subsets with different expression patterns from protein collections. Proteins with similar expression patterns may have similar functions or participate in the same biological pathway.

GO functional classification was shown in Figure 4. In group A and group B, the functions of most DEPs were related to catalytic activity, binding, structural molecule activity, transporter activity, and antioxidant activity. Most DEPs participated in metabolic processes, cellular processes, response to stimuli, localization, biological regulation, cellular component of organization or biogenesis, and other important biological processes. Notably, the amounts of DEPs related to catalytic activity in group B were much larger than group A.

A

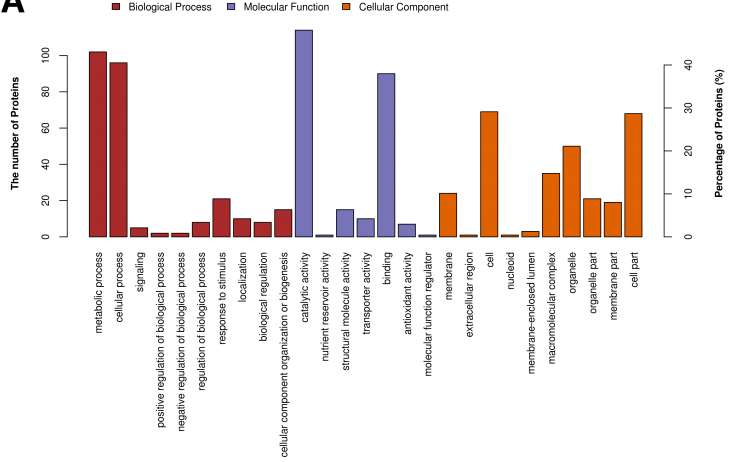

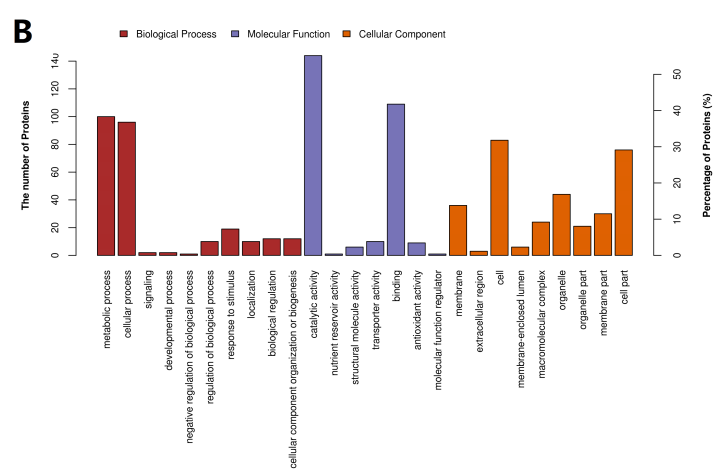

Figure 4. GO functional classification of DEPs. (A) Group A, $20 \mathrm{~g} / \mathrm{L} \mathrm{NaCl}$ addition vs. control; (B) Group B, $70 \mathrm{~g} / \mathrm{L} \mathrm{NaCl}$ addition vs. control.

Enriched GO terms are shown in Figure 5. GO enrichment analysis identified tetrapyrrole binding, heme binding, catalase activity, hydrogen peroxide catabolic process, response to oxidative stress, peroxidase activity, response to stress, reactive oxygen species' metabolic 
process, hydrogen peroxide metabolic process, and valyl-tRNA aminoacylation activity that underwent significant changes in group A, while serine hydrolase activity, serine-type peptidase activity, heme binding, tetrapyrrole binding, carboxypeptidase activity, peroxidase activity, antioxidant activity, hydrogen peroxide catabolic process, catalase activity, and carbohydrate metabolic process showed significant changes in group B.

A

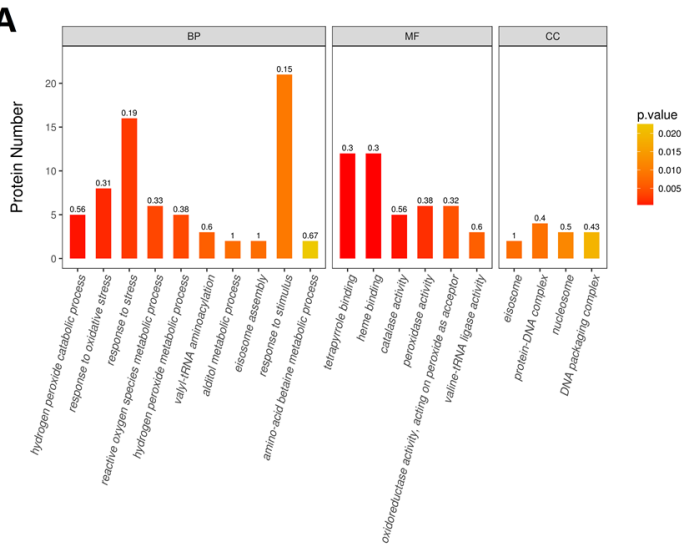

B

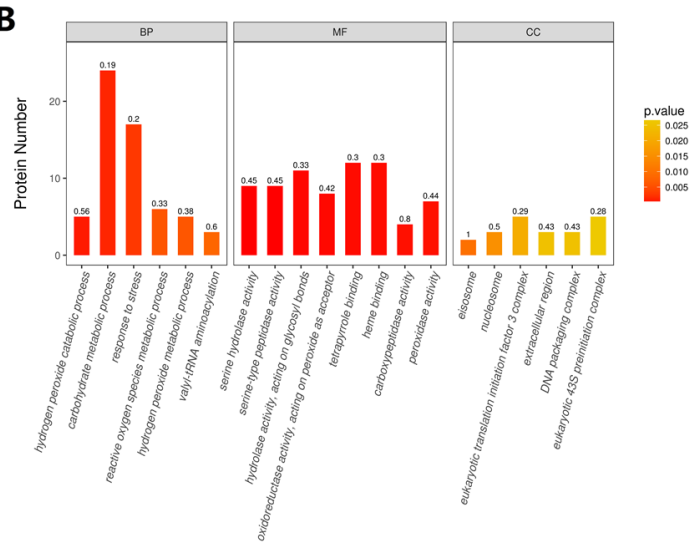

Figure 5. GO enrichment analysis of DEPs. The enrichment value represents the ratio of the number of DEPs vs. the total number of identified proteins annotated to the GO functional category. (A) Group A, 20 g/L NaCl addition vs. control; (B) Group B, $70 \mathrm{~g} / \mathrm{L} \mathrm{NaCl}$ addition vs. control.

KEGG pathway enrichment results are shown in Figure 6. KEGG pathway enrichment analysis indicated that proteins involved in MAPK (mitogen activated protein kinase) signaling pathway, peroxisome, longevity regulating pathway, FoxO signaling pathway, and tryptophan metabolism were significantly regulated in two groups. However, proteins related to estrogen signaling pathway, NOD (nucleotide-binding and oligomerisation domain-containing protein)-like receptor signaling pathway, glyoxylate and dicarboxylate metabolism, and steroid biosynthesis were significantly regulated in group B.

A

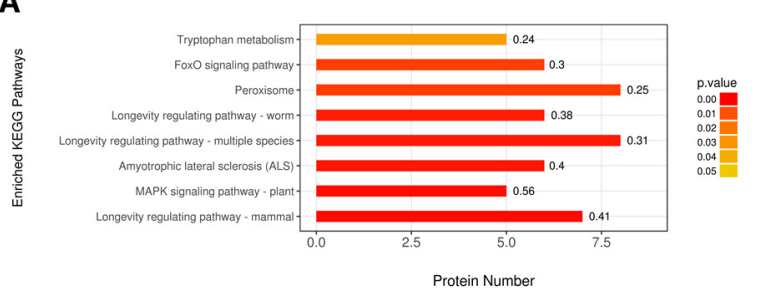

B

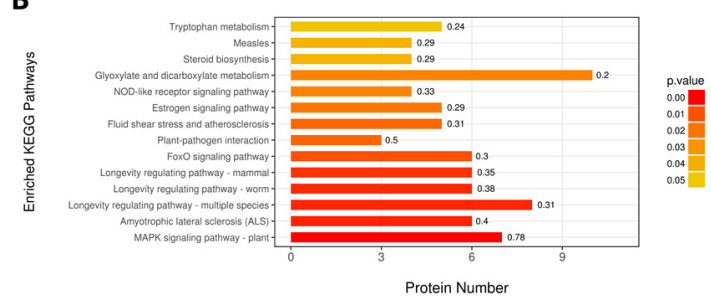

Figure 6. KEGG enrichment analysis of DEPs. The enrichment value represents the ratio of the number of DEPs vs. the total number of identified proteins annotated to the KEGG pathway category; (A) $20 \mathrm{~g} / \mathrm{L} \mathrm{NaCl}$ addition vs. control; (B) $70 \mathrm{~g} / \mathrm{L}$ $\mathrm{NaCl}$ addition vs. control.

\subsection{Classification of DEPs}

Because of the limited studies on A. ochraceus and the database with relatively few relevant entries, some functions of DEPs remain uncharacterized. Even so, many DEPs were selected and classified into categories of extracellular hydrolase, ergosterol synthesis pathway-related enzymes, cell cycle-related proteins, energy metabolism-related enzymes, non-phosphorylated oxidoreductases, antioxidant defense system-related proteins, protein synthesis-related proteins, chaperones, autophagy -elated proteins, and secondary metabolite synthase, as shown in Table 1. 
Table 1. Selected differentially expressed proteins.

\begin{tabular}{|c|c|c|c|}
\hline Protein ID & Protein Name & $\log _{2} A^{1}$ & $\log _{2} B^{1}$ \\
\hline \multicolumn{4}{|l|}{ Nutrient uptake } \\
\hline A0A2I2GMT7 & Neutral protease 2 & 1.72 & 2.10 \\
\hline A0A2I2GLV5 & Secreted lipase & $\mathrm{N}$ & 2.03 \\
\hline Q0CPJ4 & Endoglucanase 3 & $\mathrm{~N}$ & 1.74 \\
\hline \multicolumn{4}{|c|}{ Ergosterol synthesis pathway } \\
\hline A0A2I2GRQ5 & Cyp51A (ERG11) & 1.71 & $\mathrm{~N}$ \\
\hline A0A2I2G1P7 & C-14 sterol reductase (ERG24) & $\mathrm{N}$ & 2.00 \\
\hline A0A0U5G2H3 & Putative C-8 sterol isomerase (ERG2) & 1.81 & 1.65 \\
\hline A0A2I2GQM9 & Cytochrome P450 (ERG5) & 1.64 & 2.19 \\
\hline \multicolumn{4}{|l|}{ Cell cycle } \\
\hline A0A1L9RRV9 & Cell cycle arrest protein (BUB3) & 2.02 & $\mathrm{~N}$ \\
\hline Q5BGV2 & DNA helicase (MCM6) & 1.61 & $\mathrm{~N}$ \\
\hline A0A1E3BQY7 & $\begin{array}{l}\text { Serine/threonine-protein phosphatase 2A } \\
\text { regulatory subunit A (PP2A) }\end{array}$ & 1.53 & $\mathrm{~N}$ \\
\hline \multicolumn{4}{|l|}{ Glycolysis } \\
\hline A0A0F8XU69 & Glucose-6-phosphate isomerase & 0.61 & 0.66 \\
\hline A0A2I1C3N2 & Fructose-bisphosphate aldolase, class II & 1.57 & $\mathrm{~N}$ \\
\hline A0A254U7 $\times 1$ & Triosephosphate isomerase & 1.52 & $\mathrm{~N}$ \\
\hline A1CD39 & $\begin{array}{c}\text { Glyceraldehyde-3-phosphate } \\
\text { dehydrogenase }\end{array}$ & 0.62 & $\mathrm{~N}$ \\
\hline P20445 & $\begin{array}{l}\text { Glyceraldehyde-3-phosphate } \\
\text { dehydrogenase }\end{array}$ & $\mathrm{N}$ & 0.65 \\
\hline A0A1R3RQC6 & $\begin{array}{l}\text { 2,3-bisphosphoglycerate-independent } \\
\text { phosphoglycerate mutase }\end{array}$ & 0.60 & $\mathrm{~N}$ \\
\hline \multicolumn{4}{|l|}{ Citric acid cycle } \\
\hline Q0CIX6 & Malate dehydrogenase & $\mathrm{N}$ & 0.39 \\
\hline A0A1F8AGJ2 & Malate dehydrogenase & $\mathrm{N}$ & 0.60 \\
\hline Q2ULH0 & Aconitate hydratase, mitochondrial & $\mathrm{N}$ & 0.61 \\
\hline \multicolumn{4}{|l|}{ Respiratory chain } \\
\hline A0A0F8WWK6 & $\begin{array}{l}\text { Putative NADH-ubiquinone } \\
\text { oxidoreductase } 39 \text { kDa subunit }\end{array}$ & $\mathrm{N}$ & 0.56 \\
\hline A0A2I2FTY0 & $\begin{array}{l}\text { Putative NADH-ubiquinone } \\
\text { oxidoreductase subunit B }\end{array}$ & $\mathrm{N}$ & 0.60 \\
\hline A0A1M3TZM0 & $\begin{array}{l}\text { Mitochondrial succinate dehydrogenase } \\
\text { assembly factor } 2\end{array}$ & $\mathrm{~N}$ & 0.65 \\
\hline A0A2I2GQA1 & $\begin{array}{l}\text { Non-heme } 11 \text { kDa protein of cytochrome } \\
\text { bc1 complex }\end{array}$ & $\mathrm{N}$ & 1.71 \\
\hline A0A2G7FY34 & $\begin{array}{l}\text { Cytochrome c oxidase assembly protein } \\
\text { (COX19) }\end{array}$ & 1.85 & 3.67 \\
\hline A0A2I2GGG7 & COX5A-domain-containing protein & 1.68 & $\mathrm{~N}$ \\
\hline A0A2I2GKR3 & Cytochrome c oxidase subunit 7A & 1.58 & $\mathrm{~N}$ \\
\hline A0A1M3T952 & Cytochrome c oxidase subunit 5b (COX5B) & 1.57 & $\mathrm{~N}$ \\
\hline A0A254TW86 & COX assembly mitochondrial protein & $\mathrm{N}$ & 1.75 \\
\hline A0A2I2GS70 & Cytochrome c oxidase subunit & $\mathrm{N}$ & 1.72 \\
\hline H6S076 & Cytochrome c oxidase subunit 1 & $\mathrm{~N}$ & 0.51 \\
\hline A0A0F8V271 & ATP synthase subunit alpha & 1.71 & $\mathrm{~N}$ \\
\hline A0A0L1J0I5 & ATP synthase subunit alpha & 0.62 & 0.50 \\
\hline A0A2I2FVN7 & F-type $\mathrm{H}^{+}$-transporting ATPase subunit $\mathrm{g}$ & 0.65 & 0.64 \\
\hline A0A2I2G857 & ATP synthase subunit beta & $\mathrm{N}$ & 0.58 \\
\hline A0A1L9UVI1 & Plasma membrane ATPase & $\mathrm{N}$ & 0.46 \\
\hline A0A2I2G2E3 & $\begin{array}{l}\text { Cytochrome b5-like heme binding } \\
\text { domain-containing protein }\end{array}$ & 2.08 & 1.66 \\
\hline
\end{tabular}


Table 1. Cont.

\begin{tabular}{|c|c|c|c|}
\hline Protein ID & Protein Name & $\log _{2} A^{1}$ & $\log _{2} B^{1}$ \\
\hline \multicolumn{4}{|c|}{ Non-phosphorylated redox reaction } \\
\hline A0A2I2GRW8 & Putative cytochrome b5 & 1.53 & 4.10 \\
\hline A1CEK3 & Putative cytochrome b5 & $\mathrm{N}$ & 2.44 \\
\hline A0A1L9U588 & $\begin{array}{l}\text { Sulfite reductase (NADPH) hemoprotein } \\
\text { beta-component }\end{array}$ & 2.02 & $\mathrm{~N}$ \\
\hline A0A2I2GR30 & Assimilatory sulfite reductase & 1.61 & $\mathrm{~N}$ \\
\hline A0A2I2G6M7 & $\begin{array}{l}\text { FAD/NAD(P)-binding domain-containing } \\
\text { protein }\end{array}$ & 1.80 & $\mathrm{~N}$ \\
\hline A0A0K8LSM9 & $\begin{array}{l}\text { Mitochondrial 5-demethoxyubiquinone } \\
\text { hydroxylase }\end{array}$ & 1.61 & $\mathrm{~N}$ \\
\hline A0A2I2G2W0 & Thioredoxin & 1.57 & 2.48 \\
\hline A0A2I2G575 & Thioredoxin-domain-containing protein & $\mathrm{N}$ & 1.92 \\
\hline Q0CW86 & Protein disulfide-isomerase (tigA) & 1.77 & 2.72 \\
\hline G3Y6N5 & Protein disulfide isomerase & 1.52 & 1.66 \\
\hline \multicolumn{4}{|c|}{ Antioxidant defense system } \\
\hline A0A2P2H6U1 & Peroxidase & 1.54 & 1.72 \\
\hline A0A1L9S160 & Peroxidase & $\mathrm{N}$ & 1.67 \\
\hline A0A2G7FRT8 & Superoxide dismutase & 2.18 & 3.80 \\
\hline A0A2I2FSX8 & $\mathrm{Cu}, \mathrm{Zn}$ superoxide dismutase-like protein & 1.56 & 2.47 \\
\hline A0A0F8UM10 & Catalase & 3.32 & 5.24 \\
\hline A0A1L9RM09 & Catalase & 2.18 & 3.69 \\
\hline A0A0F0IKG0 & Catalase & 1.87 & 2.69 \\
\hline A0A2I2GCH5 & Catalase & 1.79 & 1.93 \\
\hline A0A2I2FWF9 & Catalase & 1.71 & 2.63 \\
\hline A0A1L9WU32 & Glutathione S-transferase & $\mathrm{N}$ & 1.66 \\
\hline \multicolumn{4}{|c|}{ Transcription, splicing and translation } \\
\hline A0A2I2GRA8 & $\begin{array}{c}\text { DNA-directed RNA polymerase subunit } \\
\text { beta }\end{array}$ & $\mathrm{N}$ & 0.62 \\
\hline A0A2I1D678 & $\begin{array}{l}\text { Centromere/microtubule binding protein } \\
\text { (cbf5) }\end{array}$ & 0.60 & 0.54 \\
\hline A0A2I2GK37 & Nucleolar protein 58 & 0.63 & 0.54 \\
\hline A0A2I2GP60 & Nucleolar GTP-binding protein 2 & $\mathrm{~N}$ & 0.64 \\
\hline A0A2I2GCA0 & ATP-dependent RNA helicase (dbp3) & 0.59 & 0.52 \\
\hline A0A2I2FYP3 & Putative 40 S ribosomal protein S14 & 1.58 & $\mathrm{~N}$ \\
\hline A0A2I2GLK4 & $37 \mathrm{~S}$ ribosomal protein $\mathrm{S} 16$ & 0.66 & $\mathrm{~N}$ \\
\hline A0A1L9WPN8 & Small subunit ribosomal protein S18e & 0.67 & $\mathrm{~N}$ \\
\hline A0A1L9PM46 & Small subunit ribosomal protein S18e & 0.67 & $\mathrm{~N}$ \\
\hline A0A2I2FXR7 & Putative 30 S ribosomal subunit S4 & $\mathrm{N}$ & 0.62 \\
\hline A0A2I1CC93 & Ribosomal protein L24 & 1.61 & $\mathrm{~N}$ \\
\hline A0A2I2GHR7 & $60 S$ ribosomal protein L37 & 0.41 & 0.58 \\
\hline A0A1L9RUB2 & Large subunit ribosomal protein L28e & 0.51 & $\mathrm{~N}$ \\
\hline Q0СTP9 & Large subunit ribosomal protein LP1 & 0.56 & $\mathrm{~N}$ \\
\hline A0Ā1E3BC43 & $60 \mathrm{~S}$ ribosomal protein $\mathrm{L} 27 \mathrm{a}$ & 0.56 & 0.56 \\
\hline A0A2I2G2I4 & $60 S$ ribosomal protein L44 & 0.57 & $\mathrm{~N}$ \\
\hline Q0CRD9 & $60 S$ ribosomal protein L20 & 0.63 & $\mathrm{~N}$ \\
\hline A0A1L9WKW1 & Large subunit ribosomal protein L8e & 0.63 & $\mathrm{~N}$ \\
\hline A0A231MJW9 & 60 S ribosomal protein L13 & 0.65 & $\mathrm{~N}$ \\
\hline A0A2I2G636 & Ribosomal protein L22 & 0.67 & $\mathrm{~N}$ \\
\hline A0A2I2FUS3 & Ribosomal protein L4 & $\mathrm{N}$ & 0.65 \\
\hline A0A1S9D4D7 & Seryl-tRNA synthetase & 0.65 & 0.64 \\
\hline Q5BD96 & Valyl-tRNA synthetase & 0.60 & $\mathrm{~N}$ \\
\hline A0A2G7G5N0 & Valyl-tRNA synthetase & 0.66 & 0.63 \\
\hline A0A2I1C057 & Valyl-tRNA synthetase & $\mathrm{N}$ & 0.66 \\
\hline A0A0F0IBN1 & Lysyl-tRNA synthetase, class II & $\mathrm{N}$ & 0.58 \\
\hline
\end{tabular}


Table 1. Cont.

\begin{tabular}{|c|c|c|c|}
\hline Protein ID & Protein Name & $\log _{2} A^{1}$ & $\log _{2} B^{1}$ \\
\hline \multicolumn{4}{|c|}{ Transcription, splicing and translation } \\
\hline A0A0F8UQN1 & $\begin{array}{l}\text { Cofactor for methionyl-and } \\
\text { glutamyl-tRNA synthetase }\end{array}$ & $\mathrm{N}$ & 0.56 \\
\hline A0A2I2GNK9 & SnRNP assembly factor & 1.73 & 1.97 \\
\hline A1CAI8 & Putative pre-mRNA splicing factor & 1.68 & $\mathrm{~N}$ \\
\hline A0A1R3R8F2 & Pre-mRNA-processing factor 6 & 1.59 & $\mathrm{~N}$ \\
\hline A0A146FRE5 & Pre-mRNA splicing factor & 0.64 & $\mathrm{~N}$ \\
\hline A0A0F0IP01 & Translation initiation factor (1A/IF-1) & 1.61 & 1.96 \\
\hline A0A146FRB4 & Translation initiation factor (SUI1) & 0.60 & $\mathrm{~N}$ \\
\hline A0A017S0I0 & $\begin{array}{c}\text { Eukaryotic translation initiation factor } 3 \\
\text { subunit L }\end{array}$ & 0.66 & 0.60 \\
\hline A0A2I2GDK3 & $\begin{array}{c}\text { Eukaryotic translation initiation factor } 3 \\
\text { subunit D }\end{array}$ & 0.66 & 0.61 \\
\hline A0A2G7FVH8 & $\begin{array}{c}\text { Eukaryotic translation initiation factor } 3 \\
\text { subunit A }\end{array}$ & $\mathrm{N}$ & 0.58 \\
\hline A0A1L9RAX6 & $\begin{array}{c}\text { Eukaryotic translation initiation factor } 3 \\
\text { subunit L }\end{array}$ & $\mathrm{N}$ & 0.61 \\
\hline A0A2I2GJ17 & $\begin{array}{c}\text { Eukaryotic translation initiation factor } 3 \\
\text { subunit } \mathrm{E}\end{array}$ & $\mathrm{N}$ & 0.64 \\
\hline A0A1L9UG37 & Elongation factor 1-alpha & 0.64 & 0.58 \\
\hline A0A2I2FT46 & Elongation factor 1-beta & $\mathrm{N}$ & 0.62 \\
\hline \multicolumn{4}{|c|}{ Protein folding and remodeling } \\
\hline A1CEK9 & Putative ER Hsp70 chaperone (BiP) & 0.67 & 0.51 \\
\hline A0A017SPH2 & Putative Hsp70 chaperone & $\mathrm{N}$ & 0.63 \\
\hline A0A2I2FVP1 & Putative Hsp70 chaperone & 0.58 & 0.52 \\
\hline A0A017SGX5 & Heat shock protein 70 & $\mathrm{~N}$ & 0.64 \\
\hline A0A2I2FR82 & HSP90-domain-containing protein & 0.66 & 0.49 \\
\hline A0A1R3RIX4 & HSP90A (HtpG) & $\mathrm{N}$ & 0.55 \\
\hline \multicolumn{4}{|c|}{ Calcium signaling pathway } \\
\hline A0A2J5HNT7 & $\begin{array}{l}\text { Outer mitochondrial membrane protein } \\
\text { porin (VDAC2) }\end{array}$ & 1.66 & 1.87 \\
\hline A0A1L9PAT2 & Calmodulin (CALM) & $\mathrm{N}$ & 1.82 \\
\hline \multicolumn{4}{|l|}{ Autophagy } \\
\hline A0A2I2GJ12 & Aspartic endopeptidase (Pep2) & $\mathrm{N}$ & 1.66 \\
\hline A0A229X8Y1 & Saccharopepsin (PEP4) & $\mathrm{N}$ & 2.43 \\
\hline \multicolumn{4}{|c|}{ Secondary metabolism } \\
\hline A0A2I2GGR1 & Farnesyl pyrophosphate synthetase 1 & $\mathrm{~N}$ & 0.63 \\
\hline Q5D0Q7 & Nonribosomal peptide synthetase 10 & 1.7 & $\mathrm{~N}$ \\
\hline
\end{tabular}

${ }^{1} \log _{2}$ A, Group A, 20 g/L NaCl addition vs. control; $\log _{2}$ B, Group B, 70 g/L NaCl addition vs. control. N, means no significant changes were found or the proteins with $p>0.05 ; p<0.05$ for all other selected proteins.

These proteins participated in the biological process of nutrient uptake, maintaining integrity of the cell membrane, cell cycle, energy metabolism, maintaining intracellular redox homeostasis, protein synthesis and processing, autophagy, and secondary metabolism.

\section{Discussion}

Depending on the different processing technique, dry-cured meat products have a high-salt content, even above $5 \% \mathrm{NaCl}$. Due to a low water activity in these products with high- $\mathrm{NaCl}$ content, they are not susceptible to pathogens, but they have been found with the residue of OTA produced by P. nordicum and A. ochraceus. In addition, cheese also has a nearly $1.7 \% \mathrm{NaCl}$ content and could be influenced by OTA contamination. The factor was taken into consideration, and then 20 or $70 \mathrm{~g} / \mathrm{L} \mathrm{NaCl}(2 \%, 7 \%)$ was chosen as the study concentration for proteomics analysis. Notably, A. ochraceus could grow at low water activi- 
ties and high temperature. Thus, $A$. ochraceus could be a potential threat especially in the maturation process of dry-cured meat products in summer conditions [14]. The mechanism of adaption for high-salt environment by $A$. ochraceus was studied through proteomics analysis for further improvement of process and storage conditions of these products.

\subsection{Fungal Growth Promoted by $\mathrm{NaCl}$ Addition}

Our results indicated that $\mathrm{NaCl}$ addition was beneficial for the growth of $A$. ochraceus, and lower concentration of $\mathrm{NaCl}$ addition induced sporulation while high concentration repressed it.

Fungi can produce a series of extracellular enzymes, especially hydrolases, which helps them obtain nutrients from the surrounding environment [14]. Our results confirmed the influence of $\mathrm{NaCl}$ on nutrient uptake of $A$. ochraceus. The neutral protease 2, secreted lipase, and endoglucanase 3 were 2.10, 2.03, and 1.74 times upregulated in group B, while the neutral protease 2 was 1.72 times increased in group A. Upregulation of extracellular enzymes may accelerate the fungal growth. However, $70 \mathrm{~g} / \mathrm{L} \mathrm{NaCl}$ addition saw more acceleration on the secretion of extracellular enzymes than did $20 \mathrm{~g} / \mathrm{L}$.

As a component of cell membranes, sterols may affect various functions of cell membranes, such as maintaining the permeability and fluidity of cell membranes [15]. Ergosterols are found almost solely in fungi, enriched in the plasma membrane, and could be used as an indicator of fungal biomass. Four enzymes involved in ergosterol biosynthesis pathway (Figure 7) were detected as DEPs (Ergosterol ERG2, 5, 11, and 24). ERG11, ERG2, and ERG5 were significantly upregulated in group A, while ERG24, ERG2, and ERG5 were significantly upregulated in group $\mathrm{B}$. $\mathrm{NaCl}$ could upregulate the ergosterol biosynthesis pathway both in the samples with 20 and $70 \mathrm{~g} / \mathrm{L} \mathrm{NaCl}$ addition and the increased content of ergosterol could be an intuitive evidence for the acceleration on the fungal growth [16]. Further on, it may be an important mechanism for maintaining permeability of cell membrane under $\mathrm{NaCl}$ stress.

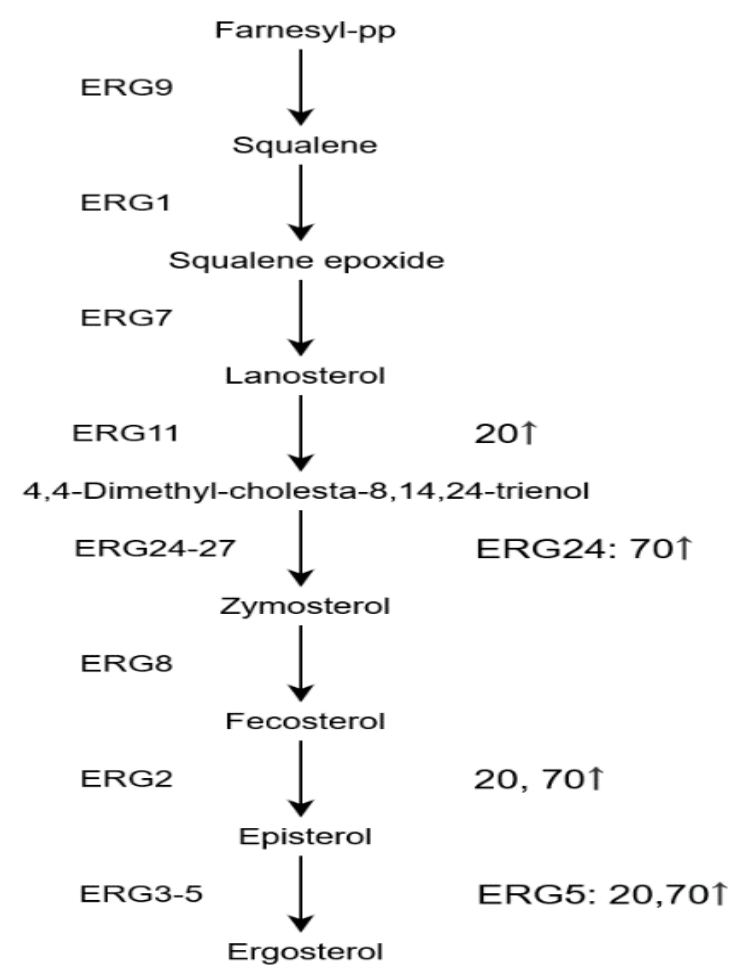

Figure 7. Specific ergosterol biosynthetic pathway and related enzymes are shown. 20: Group A, $20 \mathrm{~g} / \mathrm{L} \mathrm{NaCl}$ addition vs. control. 70: Group B, $70 \mathrm{~g} / \mathrm{L} \mathrm{NaCl}$ addition vs. control. $\uparrow$ : upregulation. 
Cell cycle-associated proteins (cell cycle arrest protein (BUB3), DNA helicase (MCM6) and serine/threonine-protein phosphatase $2 \mathrm{~A}$ regulatory subunit A (PP2A)) were 2.02, 1.61 , and 1.53 times upregulated when exposed to $20 \mathrm{~g} / \mathrm{L} \mathrm{NaCl}$, respectively. The results were consistent with the promoting effect of $20 \mathrm{~g} / \mathrm{L} \mathrm{NaCl}$ addition on fungal growth and spore production.

\subsection{Energy Metabolism and Oxidative Stress Influenced by $\mathrm{NaCl}$ Addition}

Energy metabolism was significantly affected when $\mathrm{NaCl}$ was added and the content of the enzymes related to glycolysis, tricarboxylic acid cycle, and respiratory chain were changed. Glucose-6-phosphate isomerase and glyceraldehyde-3-phosphate dehydrogenase were decreased in both groups. Fructose-bisphosphate aldolase and triosephosphate isomerase were 1.57 and 1.52 times upregulated in group A, while phosphoglycerate mutase showed downregulation. Notably, in group A, downregulation of glyceraldehyde3-phosphate dehydrogenase and upregulation of triosephosphate isomerase may induce the higher production of dihydroxyacetone phosphate and, thus, induce the higher production of glycerol, which was benefit for fungal growth under $\mathrm{NaCl}$ stress [17]. However, triosephosphate isomerase showed no significant changes when more $\mathrm{NaCl}$ was added, which may be due to the overall downregulation of energy metabolism in group B. Nevertheless, it was difficult to reveal the influence from $20 \mathrm{~g} / \mathrm{L} \mathrm{NaCl}$ addition on overall energy metabolism through analysis of glycolysis related enzymes.

Proteins related to tricarboxylic acid cycle were significantly downregulated, including two malate dehydrogenases $(0.39 ; 0.60)$ and aconitate hydratase $(0.61)$ in group B. Malate dehydrogenase could be a metabolic longevity regulator in yeast [18]. Downregulation of malate dehydrogenase could be an intuitive evidence of cell aging in the samples with $70 \mathrm{~g} / \mathrm{L} \mathrm{NaCl}$ addition. However, no significant changes of these proteins were found in group A.

Reactive oxygen species (ROS) are not only important to signal transductions but also cause cellular damages, depending on the concentration. The correct redox balance plays a crucial role in fungal growth, conidial formation, and secondary metabolism [3]. The respiratory chain could be an important source of ROS within mitochondria. The respiratory chain mainly includes four complexes, of which complexes I (NADH dehydrogenase) and Ш(cytochrome bc1 complex) are the main sources of reactive oxygen species [19]. Notably, no significant changes of complexes I- and Ш-related proteins were found in group A. However, two kinds of putative NADH-ubiquinone oxidoreductase $(0.56 ; 0.6)$ subunits were significantly downregulated and the cytochrome bc1 complex subunit was 1.71 times upregulated in group B. These results indicated that $70 \mathrm{~g} / \mathrm{L} \mathrm{NaCl}$ addition may accelerate the production of ROS within mitochondria through respiratory chain.

Moreover, other parts of respiratory chain, even including ATP synthase, were also affected by $\mathrm{NaCl}$ addition. Succinate dehydrogenase assembly factor $2(0.65)$ was decreased when $70 \mathrm{~g} / \mathrm{L} \mathrm{NaCl}$ was added. Four $(1.85,1.68,1.58,1.57)$ and three $(3.67,1.75,1.72)$ kinds of cytochrome c oxidase subunits were significantly upregulated in group A and $B$, respectively, while cytochrome c oxidase subunit 1 (0.51) showed downregulation in group B. Two and four kinds of ATP synthase subunits were decreased when 20 and $70 \mathrm{~g} / \mathrm{L}$ $\mathrm{NaCl}$ were added, respectively, and one kind of ATP synthase subunit alpha was 1.71 times upregulated in the samples with $20 \mathrm{~g} / \mathrm{L}$ addition. Downregulation of ATP synthase in the samples with $70 \mathrm{~g} / \mathrm{L} \mathrm{NaCl}$ addition represented the downregulation of energy metabolism directly. However, $20 \mathrm{~g} / \mathrm{L} \mathrm{NaCl}$ addition more slightly influenced the energy metabolism than did $70 \mathrm{~g} / \mathrm{L} \mathrm{NaCl}$ addition.

ROS are generated in several cellular systems and mitochondria may not be the main source of cellular ROS [19]. ROS can be produced by xanthine dehydrogenase in cytosol, cytochromes P450 and protein disulfide isomerase in endoplasmic reticulum, and phagocyte NADPH oxidase in plasma membrane and other oxidoreductases. The addition of $\mathrm{NaCl}$ increases the production of these kinds of proteins (using $\mathrm{FAD}^{+}, \mathrm{NAD}^{+}$, or $\mathrm{NADP}^{+}$ as an electron acceptor), including cytochrome b5, sulfite reductase, thioredoxin, and 
protein disulfide isomerase. Cytochrome b5 is a type of cytochrome P450 enzyme system that can participate in biological processes such as fatty acid synthesis, sterol synthesis, and xenobiotic metabolism. The putative cytochrome b5 (A0A2I2GRW8) was 1.53 times increased when $20 \mathrm{~g} / \mathrm{L} \mathrm{NaCl}$ was added, while it was 4.10 times increased when $70 \mathrm{~g} / \mathrm{L}$ $\mathrm{NaCl}$ was added, indicating that $\mathrm{NaCl}$ addition may cause disruption of fungal redox balance and higher concentration of $\mathrm{NaCl}$ addition made a bigger impact than did a lower concentration.

Protein disulfide isomerase and endoplasmic reticulum-resident protein were involved in the formation of disulfide bonds in proteins in the endoplasmic reticulum. Oxidative equivalents flowed into substrate protein from endoplasmic reticulum-resident protein through direct dithiol-disulfide bond exchange between protein disulfide isomerase and endoplasmic reticulum-resident protein [20]. Two protein disulfide isomerases (1.77 and 1.52 times in group A, while 2.72 and 1.66 times in group B) were significantly upregulated in two groups and $70 \mathrm{~g} / \mathrm{L} \mathrm{NaCl}$ addition seemed to have a larger influence on the proteins related to formation of intramolecular disulfide bonds than did $20 \mathrm{~g} / \mathrm{L} \mathrm{NaCl}$ addition.

Antioxidative defense system proteins were also influenced by $\mathrm{NaCl}$ addition and that could be an evidence that $\mathrm{NaCl}$ addition can cause fungal oxidative stress. Peroxidase, superoxide dismutase, catalase, and glutathione S-transferase were significantly upregulated in both groups. In detail, peroxidase (A0A2P2H6U1) was 1.54 and 1.72 times upregulated in group A and B, respectively. Peroxidase (A0A1L9S160) was 1.67 times upregulated with $70 \mathrm{~g} / \mathrm{L} \mathrm{NaCl}$ addition. Superoxide dismutase was 2.18 and 3.80 times upregulated in group A and B, respectively. Five kinds of catalase (3.32, 2.18, 1.87, 1.79, and 1.71 times in group A, while $5.24,3.69,2.69,1.93$, and 2.63 times in group B) were significantly changed by $\mathrm{NaCl}$ addition. Notably, the fold changes in group $\mathrm{B}$ were much larger than fold changes in group A. The results indicated that there was much more accumulation of ROS in the sample with $70 \mathrm{~g} / \mathrm{L} \mathrm{NaCl}$ addition than in $20 \mathrm{~g} / \mathrm{L} \mathrm{NaCl}$ addition and they conformed to the regulation of ROS production-related proteins listed above.

In brief, $20 \mathrm{~g} / \mathrm{L} \mathrm{NaCl}$ addition produced moderate ROS and induced the fungal growth and development, while higher concentration caused over accumulation of ROS and was harmful, especially in fungal development.

\subsection{Protein Synthesis and Processing Repressed by $\mathrm{NaCl}$ Addition}

Protein synthesis is directly related to ribosomes. Our results showed that ribosome biosynthesis was repressed by the presence of $\mathrm{NaCl}$. RNA polymerase I subunit beta (0.62) was significantly downregulated in the samples with $70 \mathrm{~g} / \mathrm{L} \mathrm{NaCl}$, while no significant changes were found in the sample with $20 \mathrm{~g} / \mathrm{L} \mathrm{NaCl}$. Moreover, nucleolar proteins (cbf5, nucleolar protein 58, nucleolar GTP-binding protein 2 and dbp3) related to pre-rRNA processing and most of the ribosomal proteins were downregulated in two groups. The $40 \mathrm{~S}$ ribosomal protein S14 and ribosomal protein L24 were significantly upregulated in group A, while other ribosomal proteins were repressed in two groups. Actually, the synthesis of rRNA and ribosomal proteins were coupled and downregulation of RNA polymerase I would repress pre-rRNA processing and ribosome assembly [21].

Aminoacyl-tRNA is crucial for ribosome assembly and translation. Aminoacyl-tRNA synthetase was repressed when exposed to $\mathrm{NaCl}$, including seryl-tRNA synthetase ( 0.65 times in group A, while 0.64 times in group B), valyl-tRNA synthetase $(0.60,0.66$ times, and no significant changes in group A, while no significant changes, 0.63 , and 0.66 times in group A), and lysyl-tRNA synthetase (0.58 times in group B). The effect of downregulation on the aminoacyl-tRNA synthetase was proportional to the $\mathrm{NaCl}$ concentration and the cofactor for methionyl-and glutamyl-tRNA synthetase (0.56) was downregulated in group B.

Ribosome biosynthesis is a key process of growth and constitutes a major consumer of cellular resources. This pathway is very tightly regulated to correct ribosome biosynthesis with a wide variety of environmental and metabolic change, and intracellular insults. Downregulation of ribosome biosynthesis could be an adaption for insufficient nutritional metabolism under $\mathrm{NaCl}$ stress, especially in higher concentration because of the down- 
regulation of RNA polymerase I in group B. Notably, oxidative stress represses protein synthesis by inhibiting different sub-steps of the ribosomal elongation cycle [22]. Much more accumulation of ROS in the sample with $70 \mathrm{~g} / \mathrm{L} \mathrm{NaCl}$ could be a reason for inhibiting protein synthesis.

Interestingly, pre-mRNA splicing in two groups was overall upregulated. small nuclear ribonucleoprotein (SnRNP) assembly factor was 1.73 and 1.97 times increased in the sample with 20 and $70 \mathrm{~g} / \mathrm{L} \mathrm{NaCl}$ addition, respectively. Two pre-mRNA splicing factors were upregulated and another was downregulated by the presence of $20 \mathrm{~g} / \mathrm{L} \mathrm{NaCl}$. Translation initiation factor and elongation factor were also decreased, except translation initiation factor 1A (1.61 and 1.96 time in group A and B, respectively) in two groups. The downregulation of translation initiation factor would directly decrease protein synthesis, especially in group B. Interestingly, translation initiation factor 1A is associated to abiotic stress response in Tamarix hispida [14]. Similar mechanism may exist in A. ochraceus but further study is needed.

After protein synthesis in ribosomes, peptide chain folding process was performed to form the native conformation. ATP-dependent molecular chaperones' heat shock proteins 90 (Hsp90) and 70 (Hsp70) are employed for protein folding and remodeling to maintain protein homeostasis [23]. Aqueous-exposed hydrophobic domains of client proteins are bound with Hsp70 and Hsp90 to assist sequestration of hydrophobic residues in the core of the proteins [24,25].

Our results showed that the abundances of chaperones were greatly changed with $\mathrm{NaCl}$ addition. Four kinds of Hsp70 including BIP ( 0.67 and 0.51 times in group A and $\mathrm{B}$, respectively) were significantly downregulated in group B, while two kinds of Hsp70 were significantly downregulated in group A. The Hsp90-domain-containing protein was significantly downregulated in two groups and HtpG was decreased in the samples with $70 \mathrm{~g} / \mathrm{L} \mathrm{NaCl}$ addition. However, downregulation of some chaperones may not directly cause the change of the majority relative protein concentration, because the additional workload caused by the decrease could be buffered by the capacity of other chaperones [26].

In general, protein synthesis was significantly affected, and higher oxidative stress in group B would seriously influence peptide synthesis in ribosomes. However, the specific influence of $\mathrm{NaCl}$ addition on protein processing remained unclear.

\subsection{Signal Transduction and Autophagy Activated by $\mathrm{NaCl}$ Addition}

Fungal $\mathrm{Ca}^{2+}$ signaling pathway and autophagy were found affected when $\mathrm{NaCl}$ was added.

$\mathrm{Ca}^{2+}$ signaling pathway-related proteins including outer mitochondrial membrane protein porin (VDAC2) and calmodulin (CALM) were significantly regulated, especially in group B. VDAC2 and CALM were 1.87 and 1.82 times changed in the samples with $70 \mathrm{~g} / \mathrm{L} \mathrm{NaCl}$ addition, indicating the disorder of cellular $\mathrm{Ca}^{2+}$ signaling pathway. Actually, the influence of $\mathrm{NaCl}$ on cellular $\mathrm{Ca}^{2+}$ is predictable because of the presence of $\mathrm{Na}^{+} / \mathrm{Ca}^{2+}$ exchangers and competition between the extracellular $\mathrm{Ca}^{2+}$ and $\mathrm{Na}^{+}$[27].

BIP (Hsp70) was a regulator for $\mathrm{Ca}^{2+}$ homeostasis in endoplasmic reticulum (ER) and could induce autophagy when unfolded/misfolded protein was in over accumulation [28]. Aspartic endopeptidase (PEP2) and saccharopepsin (PEP4) were aspartic-type endopeptidases as a component of mTORC1 (mammalian target of rapamycin) complex, associated with autophagy. PEP2 (1.66) and PEP4 (2.43) were found upregulated in the sample with $70 \mathrm{~g} / \mathrm{L} \mathrm{NaCl}$ addition. The finding confirmed the nutrient starvation condition of $A$. ochraceus when exposed to $70 \mathrm{~g} / \mathrm{L} \mathrm{NaCl}$. However, $20 \mathrm{~g} / \mathrm{L} \mathrm{NaCl}$ addition would not induce the expression of PEP2 and PEP4.

\subsection{Fungal Secondary Metabolism Affected by $\mathrm{NaCl}$ Addition}

In secondary metabolism, backbone enzymes are preformed to form carbon backbones using central metabolites, that is, polyketide synthases (PKSs) and terpene synthases assembling acyl-CoAs, and NRPSs (non-ribosomal peptide synthetase) link-up amino acids. 
Then, tailoring enzymes, such as methyltransferases, p450 monooxygenases, hydroxylases, and epimerases, are subsequently used for further modification.

Our result showed that farnesyl pyrophosphate synthetase 1 was decreased in the samples with $70 \mathrm{~g} / \mathrm{L} \mathrm{NaCl}$ addition, and nonribosomal peptide synthetases (NRPS) 10 was 1.70 times increased in the samples with $20 \mathrm{~g} / \mathrm{L} \mathrm{NaCl}$ addition. In the previous study, Aoota A (PKS) was 10.5 and 0.4 times changed with 20 and $70 \mathrm{~g} / \mathrm{L} \mathrm{NaCl}$ addition, respectively, while AootaB (NRPS) was 2.5 and 0.6 times changed [12]. The results were consistent with proteomics analysis that $20 \mathrm{~g} / \mathrm{L} \mathrm{NaCl}$ addition may induce secondary metabolisms while $70 \mathrm{~g} / \mathrm{L} \mathrm{NaCl}$ addition repressed it.

\section{Conclusions}

The $\mathrm{NaCl}$ addition could induce fungal growth, but only low- $\mathrm{NaCl}$ concentration could induce spore production while high- $\mathrm{NaCl}$ concentration repressed it. Comparative proteomics analysis of $A$. ochraceus with 20 and $70 \mathrm{~g} / \mathrm{L} \mathrm{NaCl}$ addition was performed in this paper, and the results revealed significant perturbation of proteins involved in nutrient uptake, cell membrane integrity, cell cycle, energy metabolism, intracellular redox homeostasis, protein synthesis and processing, autophagy, and secondary metabolism, including repression of OTA production by A. ochraceus depending on its concentration. More extracellular hydrolase for adaption of nutrient starvation was produced, caused by downregulation of energy metabolism, especially in higher concentration of $\mathrm{NaCl}$ addition. The main difference was due to the intracellular ROS. Higher ROS concentration was harmful to protein synthesis and even caused autophagy when exposed to higher concentration of $\mathrm{NaCl}$. Meanwhile, secondary metabolism including OTA production was induced when $20 \mathrm{~g} / \mathrm{L} \mathrm{NaCl}$ was added and repressed when $70 \mathrm{~g} / \mathrm{L}$ was added. The mechanism of adaption for high-salt environment by A. ochraceus was studied through proteomics analysis for further improvement of process and storage conditions of these salty foodstuffs.

\section{Materials and Methods}

\subsection{Strains, Media, and Culture Conditions}

A. ochraceus fc-1 was sequenced [9] and used in this work.

Potato dextrose agar (PDA; potato $200 \mathrm{~g} / \mathrm{L}$, glucose $20 \mathrm{~g} / \mathrm{L}$, agar $20 \mathrm{~g} / \mathrm{L}$ ) and yeast extract sucrose (YES; $20 \mathrm{~g} / \mathrm{L}$ yeast extract, $150 \mathrm{~g} / \mathrm{L}$ sucrose) were used. Spores were collected from 7-day-old fungal colonies grown on PDA at $28{ }^{\circ} \mathrm{C}$. Spore suspensions concentrations were counted using a hemocytometer (Yuanye Bio, Shanghai, China) and changed to $10^{7}$ conidia/mL by $25 \%$ glycerol solution. Spore suspensions were stored at $-80^{\circ} \mathrm{C}$ for further research.

YES was used in proteomics research, while PDA was used to record colony diameters and detect OTA content. Culture media were prepared by adding 0,20 , and $70 \mathrm{~g} / \mathrm{L} \mathrm{NaCl}$ into PDA or YES, followed by autoclaving at $121^{\circ} \mathrm{C}$ for $20 \mathrm{~min}$. The cultures proceeded at $28^{\circ} \mathrm{C}$ in a constant temperature incubator.

\subsection{Mycelial Growth and Conidia Production Assessments}

To evaluate the influence of $\mathrm{NaCl}$ on fungal mycelial growth, growth assessments were performed by adding $5 \mu \mathrm{L}$ spore suspensions on the center of the PDA media in a petri dish. The mycelial diameters were recorded every $12 \mathrm{~h}$ until $84 \mathrm{~h}$, and the graph was plotted according to the changes of mycelial diameter against time.

The mycelial growth rate was calculated by the following formula: growth rate $(\%)=\left(\mathrm{T}_{2}-\mathrm{T}_{1} / \mathrm{T}_{1}\right) \times 100 \%$, where $\mathrm{T}_{1}$ is the mean colony diameter at a certain time and $T_{2}$ is the respective value after $12 \mathrm{~h}$.

The amount of conidia was counted using a hemocytometer (Yuanye Bio) after culture for four days. Briefly, five agar plugs (diameter: $8 \mathrm{~mm}$ ) were collected from the colony, transferred into $10-\mathrm{mL}$ micro reaction tubes, and $5 \mathrm{~mL}$ of $0.01 \%$ sterile Tween 80 aqueous 
solution was added. The spore suspensions were homogenized for $2 \mathrm{~h}$ on a rotary shaker before conidia count.

All assays were replicated in triplicate.

\subsection{OTA Detection}

For determination of OTA production, high-performance liquid chromatography (HPLC) analysis was employed. Briefly, after seven days of culture on PDA, five agar plugs (diameter: $8 \mathrm{~mm}$ ) were collected from the colony, transferred into 2-mL micro reaction tubes, and $1 \mathrm{~mL}$ of methanol was added. The OTA was extracted for $2 \mathrm{~h}$ on a rotary shaker and the supernatants were collected, filtered through a $0.22-\mu \mathrm{m}$ filter, and stored at $-20{ }^{\circ} \mathrm{C}$ for further test.

The HPLC equipment included an Agilent 1260 series system (Agilent, Berks., UK) with a fluorescence detector and an autosampler. Analysis was performed in the isocratic mode and the mobile phase was acetonitrile:water:acetic acid $(99: 99: 2 v / v / v)$ at a flow rate of $1 \mathrm{~mL} / \mathrm{min}$. The injection volume was $20 \mu \mathrm{L}$. Fluorescence detection (FLD) was used at an excitation wavelength of $330 \mathrm{~nm}$ and an emission wavelength of $460 \mathrm{~nm}$, using a C18 column (Agilent; $150 \mathrm{~mm} \times 4.6 \mathrm{~mm}, 5 \mu \mathrm{m}$ ). Pure OTA (Sigma, St. Louis, USA) was used as standard.

All assays were replicated in triplicate.

\subsection{Proteomic Analysis}

To analyze the influence of $\mathrm{NaCl}$ on fungal growth and development in the molecular insights, iTRAQ-based proteomic analysis was performed according to the protocol from the producer (AB SCIEX, Foster City, CA, USA). Briefly, the mycelia were collected from liquid YES media after culture for five days in a 250-mL Erlenmeyer flask, snap-frozen in liquid nitrogen, and stored at $-80^{\circ} \mathrm{C}$ until extraction.

SDT buffer ( $4 \%(w / v)$, sodium dodecyl sulphate, $100 \mathrm{mM}$ TRIS/HCL (pH 7.6), and $0.1 \mathrm{M}$ dithiothreitol) was used for protein extraction, and then bicinchoninic acid assays were used for protein quantification, followed by trypsin digestion using the filter-aided proteome preparation (FASP) method. Digested samples were desalted prior to analysis using a C18 cartridge. After lyophilization of peptides, $40 \mu \mathrm{L}$ dissolution buffer was added and peptides were quantified spectrophotometrically at a $\mathrm{A}_{280}$.

Then, $100 \mu \mathrm{g}$ of peptide was labeled for each sample. Strong cation exchange (SCX) chromatography was performed using an AKTA Purifier 100 (AKTA, Sweden) with buffer A (10 mM KH $\mathrm{PO}_{4}$ and $\left.25 \% \mathrm{ACN}(\mathrm{pH} 3.0)\right)$ and buffer B (10 mM KH $\mathrm{PO}_{4}, 500 \mathrm{mM} \mathrm{KCL}$, and $25 \% \mathrm{ACN}$ (pH 3.0)). For separation, the sample was loaded from the ejector onto a column equilibrated with buffer $\mathrm{A}$. The gradient elution conditions were as follows: 0-25 min, 0-10\% B; 25-32 min, 10-20\% B; 32-42 min, 20-45\% B; $42-47 \mathrm{~min}, 45-100 \%$ B; $47-60 \mathrm{~min}, 100 \% \mathrm{~B}$; after $60 \mathrm{~min}, 0 \% \mathrm{~B}$. $\mathrm{A}_{214}$ was recorded during elution, and eluted fractions were collected every minute, lyophilized, and desalted using a $C_{18}$ cartridge.

Each fractionated sample was separated by HPLC Easy nLC (Thermo Fisher Scientific, Waltham, USA) at a nanoliter flow rate. The solvents of $0.1 \%$ formic acid (solvent A) and $0.1 \%$ formic acid acetonitrile aqueous solution ( $84 \%$ acetonitrile; solvent B) were used as mobile phase. The column was equilibrated with $95 \%$ solvent A. Samples were loaded from the autosampler into the loading column using an Acclaim PepMap100 (Thermo Fisher Scientific; $100 \mu \mathrm{m} \times 2 \mathrm{~cm}$, nanoViper $\mathrm{C}_{18}$ ) and separated by an EASY analytical column (Thermo Fisher Scientific; $10 \mathrm{~cm}, 75-\mu \mathrm{m}$ internal diameter, $3 \mu \mathrm{m}, \mathrm{C}_{18}-\mathrm{A} 2$ ) with a flow rate of $300 \mathrm{~nL} / \mathrm{min}$.

The sample was subjected to mass spectrometry using a Q-Exactive mass spectrometer (Thermo Fisher Scientific). The mass spectrometer data were acquired in positive ion mode with a selected mass range of 300-1800 m/z, and used for high-energy collisional dissociation (HCD) fragmentation. The automatic gain control (AGC) target was set to e6, the maximum injection time (IT) was $50 \mathrm{~ms}$, and the dynamic exclusion time was $60 \mathrm{~s}$. Polypeptides and polypeptide fragments were collected based on mass-to-charge ratio, 
and 20 MS2 (activation-type HCD) scans were done during each full scan. The resolution of HCD spectrum was set to 17,500 at $200 \mathrm{~m} / \mathrm{z}$, and the isolation window was $2 \mathrm{~m} / \mathrm{z}$. The normalized collision energy was $30 \mathrm{eV}$ and the under fill was $0.1 \%$.

\subsection{Data Analysis}

Statistical analyses of mycelial growth, conidia production, and OTA production were performed by Microsoft Excel (2019). Means comparison was analyzed through Duncan's multiple-range test and $p<0.05$ was considered statistically significant.

Proteomics analysis was performed using the Mascot search engine (http:/ / www. matrixscience.com/; v.2.2.0) and Proteome Discoverer (Thermo Fisher Scientific; v.1.4.0). Tandem mass spectra were searched on the UniProt_Aspergillus_543324_20180705 database (http:/ /www.uniprot.org/). Trypsin was designated as the cleavage enzyme, and up to two missed cuts were allowed. For precursor ions, the mass tolerance was set to $20 \mathrm{ppm}$, and for fragment ions, the mass tolerance was set to $0.1 \mathrm{Da}$. For protein quantification, the protein ratios were calculated as the median of only unique peptides for each protein, and the false detection rate (FDR) was adjusted to $<0.01$. Data correction was based on the median protein ratios after normalizing of all peptide ratios, and the normalized protein median is 1.

Blast2GO (http: / / www.blast2go.de) was used for analysis of Gene Ontology (GO) annotation, together with BLAST searching, mapping, annotation, and InterProScan annotation. The Kyoto Encyclopedia of Genes and Genomes (KEGG) pathway database was used to predict target proteins using the KEGG Automatic Annotation Server (KAAS). Fisher's exact tests were carried out to compare the distribution of each GO classification and KEGG pathway for the target protein set and the entire proteome, and the target protein set was subjected to enrichment analysis based on GO annotation and KEGG pathway annotation.

Protein clustering analysis was performed to standardize the quantitative information for the target protein set $(-1,1)$. Complex heatmap (Bioconductor; v.3.4.0) was then used to classify protein expression levels and to generate a hierarchical cluster heatmap.

All assays were replicated in duplicate. Differentially expressed proteins (DEPs) were filtered according to the significance A method [29] and $p<0.05$.

Supplementary Materials: The following are available online at https:/ / www.mdpi.com/2072-665 1/13/1/51/s1, Figure S1: Hierarchical cluster analysis of DEPs.

Author Contributions: Conceptualization, Y.W. and H.Y.; methodology, Y.W.; formal analysis, W.L. and Y.G.; validation, H.Y.; writing—original draft preparation, W.L. and Y.W.; writing—review and editing, J.N. and Y.W.; project administration, Y.W. and P.S.; funding acquisition, Y.W. All authors have read and agreed to the published version of the manuscript.

Funding: This research was funded by the Key Research and Development Projects of Zhejiang (2021C02058), the Youth Program of the National Natural Science Foundation of China (31601577), and the Central Public-interest Scientific Institution Basal Research Fund (2019).

Institutional Review Board Statement: Not applicable.

Informed Consent Statement: Not applicable.

Acknowledgments: We thank all the members of Peilong Sun's laboratory who contributed to this work.

Conflicts of Interest: The authors declare no conflict of interest.

\section{References}

1. Iacumin, L.; Milesi, S.; Pirani, S.; Comi, G.; Chiesa, L.M. Ochratoxigenic mold and Ochratoxin A in fermented sausages from different areas in Northern Italy: Occurrence, reduction or prevention with ozonated air. J. Food Saf. 2011, 31, 538-545. [CrossRef]

2. Khaneghah, A.M.; Fakhri, Y.; Abdi, L.; Coppa, C.; Franco, L.T.; de Oliveira, C.A.F. The concentration and prevalence of ochratoxin A in coffee and coffee-based products: A global systematic review, meta-analysis and meta-regression. Fungal Biol. 2019, 123, 611-617. [CrossRef] [PubMed] 
3. Wang, Y.; Wang, L.; Liu, F.; Wang, Q.; Selvaraj, J.N.; Xing, F.; Zhao, Y.; Liu, Y. Ochratoxin A producing fungi, biosynthetic pathway and regulatory mechanisms. Toxins 2016, 8, 83. [CrossRef] [PubMed]

4. Iacumin, L.; Chiesa, L.; Boscolo, D.; Manzano, M.; Cantoni, C.; Orlic, S.; Comi, G. Moulds and ochratoxin A on surfaces of artisanal and industrial dry sausages. Food Microbiol. 2009, 26, 65-70. [CrossRef] [PubMed]

5. Peromingo, B.; Nunez, F.; Rodriguez, A.; Alia, A.; Andrade, M.J. Potential of yeasts isolated from dry-cured ham to control ochratoxin A production in meat models. Int. J. Food Microbiol. 2018, 268, 73-80. [CrossRef]

6. Rodriguez, A.; Medina, A.; Cordoba, J.J.; Magan, N. The influence of salt ( $\mathrm{NaCl})$ on ochratoxin A biosynthetic genes, growth and ochratoxin A production by three strains of Penicillium nordicum on a dry-cured ham-based medium. Int. J. Food Microbiol. 2014, 178, 113-119. [CrossRef]

7. Schmidt-Heydt, M.; Graf, E.; Stoll, D.; Geisen, R. The biosynthesis of ochratoxin A by Penicillium as one mechanism for adaptation to $\mathrm{NaCl}$ rich foods. Food Microbiol. 2012, 29, 233-241. [CrossRef]

8. Álvarez, M.; Rodríguez, A.; Núñez, F.; Silva, A.; Andrade, M.J. In vitro antifungal effects of spices on ochratoxin A production and related gene expression in Penicillium nordicum on a dry-cured fermented sausage medium. Food Control 2020, $114,107222$. [CrossRef]

9. Wang, Y.; Wang, L.; Wu, F.; Liu, F.; Wang, Q.; Zhang, X.; Selvaraj, J.N.; Zhao, Y.; Xing, F.; Yin, W.B.; et al. A consensus Ochratoxin A biosynthetic pathway: Insights from the genome sequence of Aspergillus ochraceus and a comparative genomic analysis. Appl. Environ. Microbiol. 2018, 84, e01009-18. [CrossRef]

10. Miller, J.; Pitt, J.; Wu, F.; Gelderblom, W.; Wild, C.; Riley, R.; Baan, R. Improving public health through mycotoxin control. In International Agency for Research on Cancer; IARC WHO: Lyon, France, 2012.

11. Ramos, A.J.; Labernia, N.; Marín, S.; Sanchis, V.; Magan, N. Effect of water activity and temperature on growth and ochratoxin production by three strains of Aspergillus ochraceus on a barley extract medium and on barley grains. Int. J. Food Microbiol. 1998, 44, 133-140. [CrossRef]

12. Wang, Y.; Yan, H.; Neng, J.; Gao, J.; Yang, B.; Liu, Y. The Influence of NaCl and Glucose content on Growth and Ochratoxin A production by Aspergillus ochraceus, Aspergillus carbonarius and Penicillium nordicum. Toxins 2020, 12, 515. [CrossRef] [PubMed]

13. Wei, Y.; Li, X.; Zhang, D.; Liu, Y. Comparison of protein differences between high- and low-quality goat and bovine parts based on iTRAQ technology. Food Chem. 2019, 289, 240-249. [CrossRef] [PubMed]

14. Canel, R.S.; Wagner, J.R.; Stenglein, S.A.; Ludemann, V. Indigenous filamentous fungi on the surface of Argentinean dry fermented sausages produced in Colonia Caroya (Cordoba). Int. J. Food Microbiol. 2013, 164, 81-86. [CrossRef] [PubMed]

15. Deng, Z.-L.; Yuan, J.-P.; Zhang, Y.; Xu, X.-M.; Wu, C.-F.; Peng, J.; Wang, J.-H. Fatty acid composition in ergosteryl esters and triglycerides from the fungus Ganoderma lucidum. J. Am. Oil Chem. Soc. 2013, 90, 1495-1502. [CrossRef]

16. Seitz, L. Ergosterol as a measure of fungal growth. Phytopathology 1979, 69, 1202. [CrossRef]

17. Gori, K.; Hebraud, M.; Chambon, C.; Mortensen, H.D.; Arneborg, N.; Jespersen, L. Proteomic changes in Debaryomyces hansenii upon exposure to $\mathrm{NaCl}$ stress. FEMS Yeast Res. 2007, 7, 293-303. [CrossRef]

18. Easlon, E.; Tsang, F.; Skinner, C.; Wang, C.; Lin, S.J. The malate-aspartate NADH shuttle components are novel metabolic longevity regulators required for calorie restriction-mediated life span extension in yeast. Genes Dev. 2008, 22, 931-944. [CrossRef]

19. Di Meo, S.; Reed, T.T.; Venditti, P.; Victor, V.M. Role of ROS and RNS Sources in Physiological and Pathological Conditions. Oxid. Med. Cell Longev. 2016, 2016, 1245049. [CrossRef]

20. Frand, A.R.; Kaiser, C.A. Ero1p oxidizes protein disulfide isomerase in a pathway for disulfide bond formation in the endoplasmic reticulum. Mol. Cell 1999, 4, 469-477. [CrossRef]

21. de la Cruz, J.; Gomez-Herreros, F.; Rodriguez-Galan, O.; Begley, V.; de la Cruz Munoz-Centeno, M.; Chavez, S. Feedback regulation of ribosome assembly. Curr. Genet. 2018, 64, 393-404. [CrossRef]

22. Willi, J.; Kupfer, P.; Evequoz, D.; Fernandez, G.; Katz, A.; Leumann, C.; Polacek, N. Oxidative stress damages rRNA inside the ribosome and differentially affects the catalytic center. Nucleic Acids Res. 2018, 46, 1945-1957. [CrossRef] [PubMed]

23. Genest, O.; Wickner, S.; Doyle, S.M. Hsp90 and Hsp70 chaperones: Collaborators in protein remodeling. J. Biol. Chem. 2019, 294, 2109-2120. [CrossRef] [PubMed]

24. Lamriben, L.; Graham, J.B.; Adams, B.M.; Hebert, D.N. N-Glycan-based ER molecular chaperone and protein quality control system: The calnexin binding cycle. Traffic 2016, 17, 308-326. [CrossRef] [PubMed]

25. Pearl, L.H. Review: The HSP90 molecular chaperone-an enigmatic ATPase. Biopolymers 2016, 105, 594-607. [CrossRef] [PubMed]

26. Jarnuczak, A.F.; Eyers, C.E.; Schwartz, J.M.; Grant, C.M.; Hubbard, S.J. Quantitative proteomics and network analysis of SSA1 and SSB1 deletion mutants reveals robustness of chaperone HSP70 network in Saccharomyces cerevisiae. Proteomics 2015, 15, 3126-3139. [CrossRef]

27. Liao, J.; Marinelli, F.; Lee, C.; Huang, Y.; Faraldo-Gomez, J.D.; Jiang, Y. Mechanism of extracellular ion exchange and binding-site occlusion in a sodium/calcium exchanger. Nat. Struct. Mol. Biol. 2016, 23, 590-599. [CrossRef] [PubMed]

28. Wang, J.; Lee, J.; Liem, D.; Ping, P. HSPA5 Gene encoding Hsp70 chaperone BiP in the endoplasmic reticulum. Gene 2017, 618, 14-23. [CrossRef]

29. Cox, J.; Mann, M. MaxQuant enables high peptide identification rates, individualized p.p.b.-range mass accuracies and proteomewide protein quantification. Nat. Biotechnol. 2008, 26, 1367-1372. [CrossRef] 